\title{
Safe healthcare: we're running out of excuses
}

\section{David P Stevens}

Ten years is a long time. A decade after the US Academy of Sciences Institute of Medicine's call to action, To err is human: Building a safer health system, ${ }^{1}$ Leape et al remind us that reliably safe healthcare remains an unfulfilled expectation globally. ${ }^{2}$ Their report offers an expanded prescription for the transformation that is needed among healthcare professionals and institutions. Their report also suggests we're running out of excuses.

Health professionals are not intentionally harmful. However, the prescription from these patient safety leaders - a call for transparency, integrated platforms of care, patient engagement, joy and meaning in work, and medical education reform-seems to collide with inertia that defies explanation. ${ }^{2}$

Fortunately, safety research has accelerated since the original IOM Report. ${ }^{3}$ Based on a perspective that includes reviewing hundreds of research papers that have been submitted to QSHC in the last five years, I suggest three additional opportunities which might provide leverage for achieving the safe systems that patients and health professionals deserve.

\section{HOW CAN WE ELEVATE HEALTHCARE SAFETY TO A FUNDAMENTAL VALUE AMONG ALL HEALTH PROFESSIONALS?}

Safety must progress to a system property in healthcare just as it has in other highrisk fields like commercial airline transport and nuclear power generation. But safety as a health system property is not enough. Safety should also be a professional value-at every level of healthcare: internationally; ${ }^{4}$ in health systems; and in every microsystem where patients and health professionals meet. Paul Bate and colleagues propose that "variation" is a sanitized word for "inequality". ${ }^{6}$ How can rationalization of unsafe healthcare be replaced with moral distress in the conscience of every healthcare professional?

Correspondence to: David P Stevens, MD, Adjunct Professor and Director, Quality Literature Program, Dartmouth Institute for Health Policy and Clinical Care, 30 Lafayette Street, Lebanon, NH 03766 USA; David.P.Stevens@Dartmouth.Edu

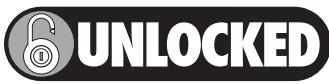

This paper is freely available online under the BMJ Journals unlocked scheme, see http://qshc.bmj.com/info/unlocked.dtl

\section{HOW DO WE EXPLOIT AN UNDERSTANDING OF CONTEXT TO EFFECT BROAD TRANSFORMATION?}

Patient safety research generally describes what works to improve safety in selected healthcare settings. The question is not only, what works? For most health professionals, it is more accurately the question, what works here? How do we learn to transform healthcare in unique and dissimilar settings? This continues to require deep inquiry into the profound meaning and role of context. ${ }^{7}$ For example, the implementation of seemingly simple strategies such as hand hygiene for health professionals or pre-operative checklists invariably requires culture change at the local microsystem level. Culture provides an excellent case in point for how local-and yet complexcontext can be. ${ }^{8}$ For instance, measuring safety culture across an institution can provide a high level perspective, but drilling down within an institution demonstrates wide variation (should we say inequality?) in safety culture. ${ }^{9}$ Saint et al report that when they tried to implement hand hygiene in five Tuscan hospitals, they found variation in the process across institutions, within institutional units, and even between doctors and nurses. ${ }^{10}$

\section{HOW MIGHT MEDICAL EDUCATORS CHANGE THE SUBJECT?}

Leape et al address the special place for medical education in the quest for safer healthcare. They emphasise the salutary role of the Six General Competencies implemented by the US Accreditation Council of Graduate Medical Education and the American Board of Medical Specialties. The Competencies place emphasis on the demonstration of practice-based learning and improvement, and systems knowledge. However, Leape et al emphasise that similar preparation is missing in early medical education. Not to put too fine a point on it, but they go so far as to say the current early medical education system prepares "square pegs for round holes".

To their list of suggested education reforms, one could add two more high leverage opportunities. First, what are the academic admissions criteria that will demonstrate that an applicant is a committed change agent? How will we encourage students and junior colleagues to question "the way we do things around here" to achieve safe healthcare? ${ }^{11}$
Second, if we want health professionals to emerge from their early formal education with the knowledge and skills that are needed to achieve safe healthcare, medical schools will need to teach to a broader test. It will include an additional assessment of the knowledge that underpins safe care. ${ }^{12}$ Good doctors still must acquire solid knowledge of the basic biological sciences for effective care. However, the disciplines that support scholarly inquiry for achieving safe care are found in the social sciences such as sociology, anthropology, and psychology and in engineering and organisational theory. These basic sciences also need to find a welcome place in medical schools.

Leape et al provide a fresh call for the will-and an outline of the policies-to achieve the universally safe healthcare that the IOM report demanded. Ten years is indeed a long time. We're running out of excuses.

Competing interests: The author is editor-in-chief of Quality and Safety in Health Care.

Provenance and peer review: not commissioned; not externally peer reviewed

Received 5 November 2009

Accepted 5 November 2009

Oual Saf Health Care 2009;18:418.

doi:10.1136/qshc.2009.038778

\section{REFERENCES}

1. Institute of Medicine. To err is human: Building a safer health system. Washington, DC: National Academies Press, 1999.

2. Leape L, Berwick D, Clancy C, et al. Transforming health care: A safety imperative. Oual Saf Health Care 2009;18:424-8.

3. Stelfox HT, Palmisani S, Scurlock C, et al. The "To Err is Human" report and the patient safety literature. Qual Saf Health Care 2006;15:174-178

4. Amalberti R, Brunae C, Degos L. Viewing the safety imperative from the French perspective. Qual Saf Health Care 2009;18:420-1.

5. Walton M. Patient safety: A view from down under Qual Saf Health Care 2009;18:422-3.

6. Bate P, Mendel P, Robert G. Organizing for Quality: The improvement journeys of leading hospitals in Europe and the United States. Oxford: Radcliffe Publishing, 2008.

7. Davidoff F, Batalden P, Stevens D, Ogrinc G, Mooney S the SOUIRE development group. Publication guidelines for quality improvement in health care: evolution of the SQUIRE project. Qual Saf Health Care 2008;17:i3-i9.

8. Liu SK, Homa K, Butterly JR, et al. Improving the simple, complicated and complex realities of community-acquired pneumonia. Qual Saf Health Care 2009;18:93-98.

9. Pronovost P, Sexton B. Assessing safety culture: Guidelines and recommendations. Qual Saf Health Care 2005;14:231-233.

10. Saint S, Conti A, Bartoloni A, et al. Improving healthcare worker hand hygiene adherence prior to patient contact: A before-snd-after 5-unit multimodal intervention in Tuscany. Qual Saf Health Care 2009;18:429-33.

11. Seiden SC, Galvan C, Lamm R. Role of medical students in preventing harm and enhancing patient safety. Qual Saf Health Care 2006;15:272-276.

12. Brown C, Hofer $T$, Johal A, et al. An epistemology of patient safety research: A framework for study design and interpretation. Part 4. One size does not fit all. Qual Saf Health Care 2008;17:178-181. 